ARTICLE

https://doi.org/10.1038/s41467-019-09750-5 OPEN

\title{
Copper(I)-catalyzed asymmetric decarboxylative Mannich reaction enabled by acidic activation of $2 \mathrm{H}$-azirines
}

Hai-Jun Zhang ${ }^{1}$, Yan-Cheng $\mathrm{Xie}^{1} \&$ Liang Yin (1) ${ }^{1}$

Chiral aziridines are structure units found in many biologically active compounds and are important building blocks in organic synthesis. Herein, by merging nucleophilic generation through copper(I)-catalyzed decarboxylation and activation of poorly electrophilic $2 \mathrm{H}$ azirines through protonation with carboxylic acids, an asymmetric decarboxylative Mannich reaction between $\alpha, \alpha$-disubstituted cyanoacetic acids and $2 \mathrm{H}$-azirines is uncovered, which leads to generation of chiral aziridines containing vicinal tetrasubstituted and acyclic quaternary stereogenic carbon centers in good to excellent diastereo- and enantioselectivities. At last, transformations of the produced chiral aziridine are successfully carried out to deliver synthetically useful compounds.

\footnotetext{
${ }^{1}$ CAS Key Laboratory of Synthetic Chemistry of Natural Substances, Center for Excellence in Molecular Synthesis, Shanghai Institute of Organic Chemistry, University of Chinese Academy of Sciences, Chinese Academy of Sciences, 345 Lingling Road, Shanghai 200032, China. Correspondence and requests for materials should be addressed to L.Y. (email: liangyin@sioc.ac.cn)
} 
$\mathrm{N}$ ature uses a mild but powerful strategy to generate a nucleophile through decarboxylation of a malonic acid half thioester in the presence of an enzyme, which is typically employed in the biosynthesis of fatty acids and polyketides ${ }^{1}$. Inspired by this fantastic method in nature, Shair and colleagues $^{2}$ developed a $\mathrm{Cu}(\mathrm{II})$-catalyzed asymmetric thioester aldol reaction, which was compatible with a broad range of protic functional groups and enolizable aldehydes due to the mild acidic reaction conditions ${ }^{2}$. Unfortunately, their following research uncovered that their reaction occurred by a different mechanism from the nature's reaction (the nucleophile was actually not generated through decarboxylation $)^{3}$. In 2009, Shibasaki and Kanai group ${ }^{4}$ mimicked the method in nature by using $\alpha$-methyla-phenyl cyanoacetic acid as a pronucleophile and accomplished a decarboxylative Mannich-type reaction of $\mathrm{N}$-diphenyl-phosphinoyl aldimines and a decarboxylative aldol reaction of aldehydes under copper(I) catalysis, which generated contiguous trisubstituted and acyclic quaternary stereocenters in moderate to high diastereo- and enantioselectivities ${ }^{4,5}$.

However, in the above two catalytic asymmetric decarboxylative reactions, cyanoacetic acid was only employed as the precursor for decarboxylative nucleophile generation ${ }^{6,7}$ by anion exchange with $\mathrm{CuOAc-bisphosphine} \mathrm{complex} \mathrm{(decarboxylative}$ protonation was a side reaction $^{8}$ ). However, the acidic nature of cyanoacetic acid was not fully utilized. Considering the basicity and the poor electrophilicity of $2 \mathrm{H}$-azirines, we propose a strategy that basic $2 \mathrm{H}$-azirines might be activated by a cyanoacetic acid through protonation to afford more electrophilic iminium species (Fig. 1) ${ }^{9,10}$. Meanwhile, the anion exchange leads to the formation of copper(I) cyanoacetate, which affords the nucleophilic copper(I) ketenimide through extrusion of $\mathrm{CO}_{2}$. Then, asymmetric addition of the nucleophilic copper(I) ketenimide to the electrophilic iminium species would allow the easy formation of a series of chiral aziridines in good yields, which contain chiral adjacent tetrasubstituted and acyclic quaternary stereocenters. These chiral aziridines would serve as intermediates to furnish synthetically useful compounds through the transformations of the aziridine functional group.

It is well known that chiral aziridines are important intermediates in organic synthesis, as they can react with nucleophiles to generate chiral amines through ring-opening reactions ${ }^{11-16}$. Moreover, chiral aziridines are structure units found in many natural products and man-made molecules, which exhibit a broad range of biological properties, such as antitumor and antibacterial activities $^{17-19}$. Therefore, the asymmetric synthesis of chiral aziridines has received significant attention from the chemical community. One of the straightforward methods is the catalytic asymmetric addition of nucleophiles to $2 \mathrm{H}$-azirines ${ }^{20,21}$. However, the lower reactivity of $2 \mathrm{H}$-azirines has led to much less developments in this area ${ }^{22-28}$. Furthermore, it is well known that the asymmetric construction of vicinal chiral tetrasubstituted (including quaternary) and acyclic quaternary carbon stereocenters $^{29-31}$ was very challenging and achieved much less success largely due to the significantly increased steric hindrance and the difficulty to control the asymmetric induction ${ }^{32-35}$.

Here, by activation of the poorly electrophilic $2 \mathrm{H}$-azirines with carboxylic acids, we disclose a copper(I)-catalyzed decarboxylative Mannich reaction of $2 \mathrm{H}$-azirines, which affords a series of chiral aziridines in good to high yields, diastereoselectivity, and enantioselectivity. More importantly, adjacent chiral tetrasubstituted and acyclic quaternary stereocenters are generated efficiently.

\section{Results}

Optimization of reaction conditions. The reaction between $\alpha$-methyl- $\alpha$-phenyl cyanoacetic acid (1a) and $2 H$-azirine $2 \mathbf{a}$ was studied for the optimization of reaction conditions as shown in Table 1. The decarboxylative Mannich reaction proceeded smoothly in the presence of $5 \mathrm{~mol} \%$ of $\mathrm{CuOAc}$ and $5 \mathrm{~mol}$ $\%$ of $(R)$-BINAP at $0^{\circ} \mathrm{C}$ in tetrahydrofuran (THF), which delivered product $3 \mathbf{a}$ in $81 \%$ yield with $2.0 / 1 \mathrm{dr}$ and $8 \%$ ee for the major diastereoisomer (Table 1, entry 1). Screening of the commercially available bisphosphine ligands, including $(R)$-TOLBINAP, $(R)$-SEGPHOS, $(R)$-DIFLUORPHOS, $(R, R)$-QUINOXP*, $(R, R)$-Ph-BPE, $\left(R, R_{P}\right)$-TANIAPHOS, $(R)$-DTBM-SEGPHOS, and $(R)$-DIPA-MeO-BIPHEP, identified $(R)$-DTBM-SEGPHOS and $(R)$-DIPA-MeO-BIPHEP as the suitable ligands (Table 1, entries 2-9). With (R)-DTBM-SEGPHOS as the ligand, product 3a was generated in $88 \%$ yield with $4.0 / 1 \mathrm{dr}$ and $93 \%$ ee for the major diastereoisomer (Table 1 , entry 8). In the case of (R)-DIPA-MeO-BIPHEP, product 3a was obtained in $62 \%$ yield with $5.7 / 1 \mathrm{dr}$ and $91 \%$ ee for the major diastereoisomer (Table 1, entry 9).

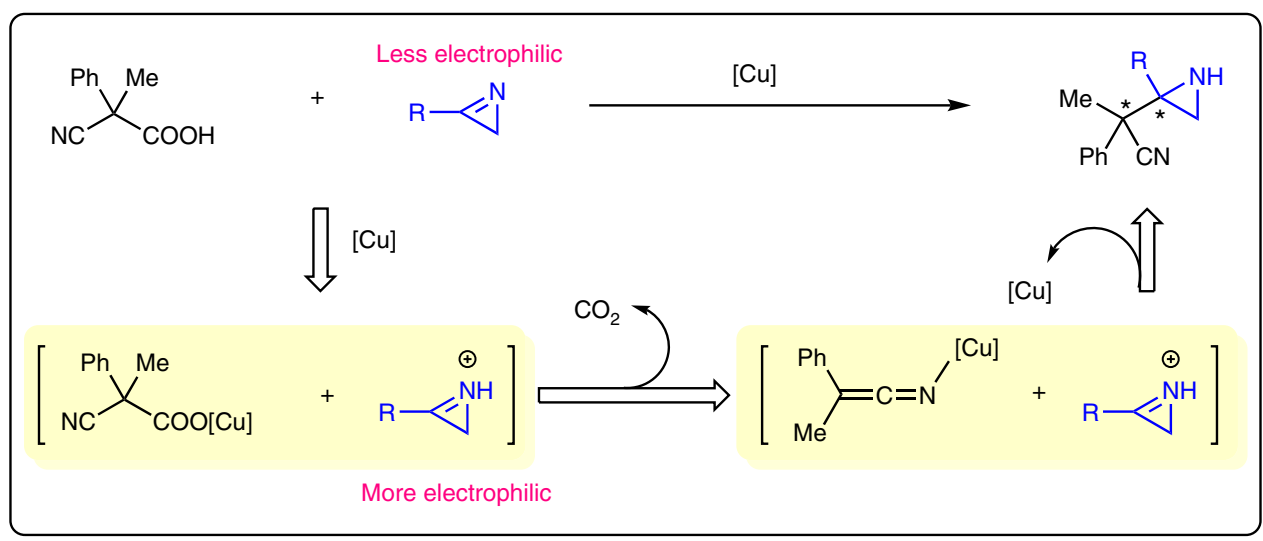

* Generation of nucleophiles through copper(I)-catalyzed decarboxylation

* Activation of poorly electrophilic $2 \mathrm{H}$-azirines with carboxylic acids

* Generation of chiral vicinal tetrasubstituted and acyclic quaternary stereocenters

${ }^{*}$ Mild but powerful acidic reaction conditions

Fig. 1 Initial design. Our working hypothesis for the catalytic asymmetric decarboxylative Mannich reaction of $2 \mathrm{H}$-azirines 


\section{Table 1 Optimization of the reaction conditions ${ }^{a}$}

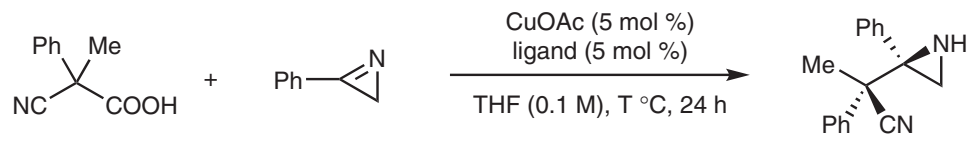

1a<smiles>[R16]c1ccc2ccccc2c1-c1c(P)ccc2ccccc12</smiles><smiles>[R7]c1ccc2c(c1-c1c([R16])ccc3c1OC([R])([R])O3)OC([R])([R])O2</smiles>

$2 a$

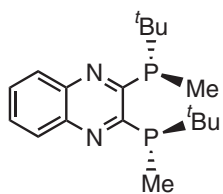

$\overline{\bar{M}}$

$\mathrm{Ar}=\mathrm{Ph}, \quad \mathrm{R}=\mathrm{H}, \mathrm{Ar}=\mathrm{Ph},(R)$-SEGPHOS; $(R, R)$-QUINOXP

$(R)$ - $\quad \mathrm{R}=\mathrm{F}, \mathrm{Ar}=\mathrm{Ph},(R)$-DIFLUORPHOS;

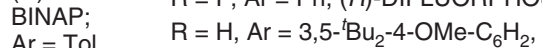

$(R)$-TOL- $\quad(R)$-DTBM-SEGPHOS

$3 a$

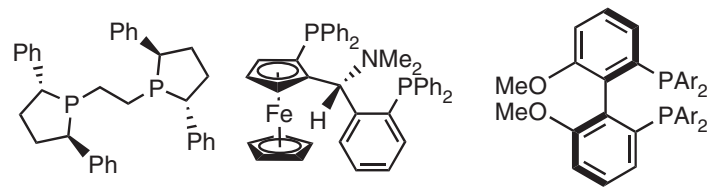

$(R, R)$-Ph-BPE $\quad\left(R, R_{p}\right)$-TANIAPHOS $\mathrm{R}=3,5-{ }^{\mathrm{i}} \mathrm{Pr}_{2}-4-\mathrm{NMe}_{2}-\mathrm{C}_{6} \mathrm{H}_{2}$,

$(R)$-DIPA-MeO-BIPHEP BINAP

\begin{tabular}{|c|c|c|c|c|c|}
\hline Entry & Ligand & $\mathrm{T}$ & yield $(\%)^{b}$ & $d r^{b}$ & ee $(\%)^{c}$ \\
\hline 1 & $(R)$-BINAP & 0 & 81 & $2.0 / 1$ & $8 / 61$ \\
\hline 2 & $(R)$-TOL-BINAP & 0 & 76 & $1.8 / 1$ & $12 / 46$ \\
\hline 3 & $(R)$-SEGPHOS & 0 & 87 & $1.8 / 1$ & $15 / 70$ \\
\hline 4 & (R)-DIFLUORPHOS & 0 & 88 & $1.7 / 1$ & $17 / 69$ \\
\hline 5 & $(R, R)$-QUINOXP* & 0 & 39 & $2.4 / 1$ & $41 / 33$ \\
\hline 6 & $(R, R)-\mathrm{Ph}-\mathrm{BPE}$ & 0 & 62 & $2.0 / 1$ & $-19 /-47$ \\
\hline 7 & $\left(R, R_{P}\right)$-TANIAPHOS & 0 & 28 & $7.3 / 1$ & $26 /-52$ \\
\hline 8 & (R)-DTBM-SEGPHOS & 0 & 88 & $4.0 / 1$ & $93 / 43$ \\
\hline 9 & (R)-DIPA-MeO-BIPHEP & 0 & 62 & $5.7 / 1$ & $91 / 55$ \\
\hline 10 & (R)-DIPA-MeO-BIPHEP & -20 & 88 & $9.1 / 1$ & $93 / 70$ \\
\hline 11 & (R)-DIPA-MeO-BIPHEP & -60 & 98 & $>20 / 1$ & $98 / 70$ \\
\hline $12^{d}$ & (R)-DIPA-MeO-BIPHEP & -60 & 99 & $>20 / 1$ & $98 / 68$ \\
\hline $13^{e}$ & $(R)$-DIPA-MeO-BIPHEP & -60 & 0 & - & - \\
\hline $14^{f}$ & - & -60 & 0 & - & - \\
\hline
\end{tabular}

a 1a: $0.3 \mathrm{mmol}$, 2a: $0.2 \mathrm{mmol}$. ${ }^{\mathrm{b}}$ Determined by ${ }^{1} \mathrm{H}$ NMR analysis of reaction crude mixture using $\mathrm{CH}_{3} \mathrm{NO}_{2}$ as an internal standard.

${ }^{c}$ Determined by chiral-stationary-phase HPLC analysis. ${ }^{\mathrm{d}} 3 \mathrm{~mol} \%$ of CuOAc and $3 \mathrm{~mol} \%$ of $(R)$-DIPA-MeO-BIPHEP were employed. $36 \mathrm{~h}$. ${ }^{e}$ Performed without CuOAc. ${ }^{f}$ Performed without $(R)$-DIPA-MeO-BIPHEP

With $(R)$-DTBM-SEGPHOS as the ligand, the studies of copper(I) source, reaction solvent, and temperature effect were not fruitful (see Supplementary Table 1-3 for details). Fortunately, decreasing the reaction temperature to $-20^{\circ} \mathrm{C}$ resulted in improved yield, diastereo-, and enantioselectivities in the case of $(R)$-DIPA-MeO-BIPHEP (Table 1, entry 10). By further lowering the reaction temperature to $-60^{\circ} \mathrm{C}$, product $3 \mathrm{a}$ was generated in $98 \%$ yield with $>20 / 1 \mathrm{dr}$ and $98 \%$ ee (Table 1 , entry $11)$. Moreover, the loading of CuOAc- $(R)$-DIPA-MeO-BIPHEP complex was successfully reduced to $3 \mathrm{~mol} \%$ by prolonging the reaction time from $24 \mathrm{~h}$ to $36 \mathrm{~h}$ (Table 1, entry 12). It was verified that both $\mathrm{CuOAc}$ and ligand $((R)$-DIPA-MeO-BIPHEP) were indispensable, as no product $\mathbf{3 a}$ was observed in the absence of either (Table 1 , entries 13, 14). The catalyst loading was further reduced to $2 \mathrm{~mol} \%$ with the success of a gram-scale reaction as shown in Fig. 2. Remarkably, $1.358 \mathrm{~g}$ of aziridine 3a was isolated in $91 \%$ yield with $>20 / 1 \mathrm{dr}$ and $97 \%$ ee.

Substrate scope. The study of the substrate scope of aromatic $2 \mathrm{H}$ azirines (2) with $3 \mathrm{~mol} \%$ of CuOAc-(R)-DIPA-MeO-BIPHEP complex was described in Table 2. Both electron-donating groups and electron-withdrawing groups were accepted at the parapositon of the phenyl group $(\mathbf{3 a}-\mathbf{3 j})$. Although the diastereoselectivity was moderate in some cases, both the yield and the 


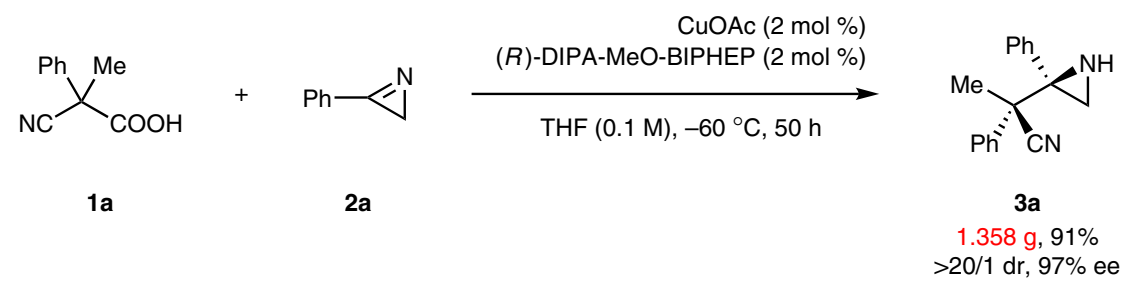

Fig. 2 Gram-scale reaction. Conditions: $\mathbf{1 a}(9 \mathrm{mmol}, 1.577 \mathrm{~g}), \mathbf{2 a}(6 \mathrm{mmol}, 0.703 \mathrm{~g}), \mathrm{CuOAc}(2 \mathrm{~mol} \%)$, ( $R$ )-DIPA-MeO-BIPHEP (2 mol \%), and THF $(60 \mathrm{~mL}),-60^{\circ} \mathrm{C}, 50 \mathrm{~h}$

enantioselectivity were high to excellent. Several aromatic $2 H$ azirines with a substituent at the meta-position served as appropriate substrates to afford the aziridines in good to excellent stereoselectivities (3k-3n). Unfortunately, a substituent was not well tolerated at the ortho-position largely due to the increased steric hindrance. $2 \mathrm{H}$-Azirine with a 2 -naphthyl group was also a suitable substrate as excellent results were obtained (3o). Moreover, both 3-thienyl and benzo[b]thiophen-2-yl groups did not have a negative effect on the reaction results (3p and $3 q)$.

Then, complex molecules containing an aromatic $2 \mathrm{H}$-azirine moiety were investigated. 2,4-Dichlorophenoxyacetic acid, a systemic herbicide, was successfully attached to the $2 \mathrm{H}$-azirine group through an ester linker (2r). 2r underwent the copper(I)catalyzed decarboxylative Mannich reaction smoothly to afford product $3 \mathbf{r}$ in excellent both yield and stereoselectivity. By using the same linker, isoxepac acid (an advanced intermediate toward the synthesis of olopatadine, which is sold as a prescription eye drop), probenecid (a medication that is primarily used in treating gout and hyperuricemia), and gabapentin (a medication that is used primarily to treat seizures and neuropathic pain) were attached with the $2 \mathrm{H}$-azirine moiety to generate $\mathbf{2 s}, \mathbf{2 t}$, and $\mathbf{2 u}$. These three $2 \mathrm{H}$-azirines reacted with 1a nicely to furnish the aziridines $(\mathbf{3 s}, \mathbf{3 t}$, and $\mathbf{3 u}$ ) in uniformly excellent yield, high diastereoselectivity, and excellent enantioselectivity. It was noted that a ketone unit, a tertiary sulfonate amide, and a secondary carbamate did not disturb both the reactivity and the stereoselectivity. Moreover, the $2 \mathrm{H}$-azirine moiety was introduced to lithocholic acid (a natural steroid molecule) through the same linker to generate a complex $2 \mathrm{H}$ azirine $(\mathbf{2 v})$, which also served as a competent substrate to furnish product $3 \mathbf{v}$ in excellent both yield and diastereoselectivities.

As (R)-DTBM-SEGPHOS led to better control of the diastereoselectivity than (R)-DIPA-MeO-BIPHEP (6/1 dr vs. 4/1 $\mathrm{dr})$ in the reaction of aliphatic $2 H$-azirine $4 \mathbf{a},(R)$-DTBMSEGPHOS was employed for the study of aliphatic $2 \mathrm{H}$-azirines (Table 3). Although the diastereoselectivity was not satisfactory in the cases of $\mathbf{5 a}$ and $\mathbf{5} \mathbf{b}$, both the yields and the enantioselectivity were excellent. The same situation was also observed in the reaction of $\alpha, \beta$-unsaturated $2 \mathrm{H}$-azirine $\mathbf{4 c}$. The aryl group in $\alpha, \alpha$-disubstituted cyanoacetic acid (1) was successfully extended to para-methyl-phenyl (1b), para-chloro-phenyl (1c), and 2-thienyl groups (1d) with high to excellent stereoselectivities (5d, 5e, and 5f). It was noted that cyanoacetic acid $\mathbf{1 c}$ with a para-chloro-phenyl led to moderate yield. Moreover, the alkyl group in 1 was successfully changed from methyl (1a) to ethyl and allyl groups (1e and 1f). Unfortunately, the yields were moderate and the diastereoselectivity decreased significantly, possibly due to the extenuated difference of the steric hindrance between phenyl and ethyl or allyl groups (5g and $5 \mathbf{h})$. Furthermore, the $2 \mathrm{H}$-azirine moiety was tethered with indometacin (a nonsteroidal anti-inflammatory drug), dehydroepiandrosterone (an endogenous steroid hormone), and a protected glucose to give three complex aliphatic $2 H$-azirines $(\mathbf{4 i}, \mathbf{4 j}$, and 4k). Their decarboxylative Mannich reactions with 1a proceeded smoothly to give the aziridines $(\mathbf{5 i}, \mathbf{5} \mathbf{j}$, and $\mathbf{5 k}$ ) in high yields with high to excellent stereoselectivities.

Demonstration of the strategy. The present decarboxylative Mannich reaction exhibited an impressive advantage over the classical proton-transfer version. As shown in Fig. 3, the protontransfer Mannich reaction of 1a' and 2 a proceeded in $<5 \%$ yield in the presence of $5 \mathrm{~mol} \%$ of CuOAc- $(R)$-DIPA-MeO-BIPHEP complex (Fig. 3b), while the decarboxylative version occurred in $98 \%$ yield (Fig. 3a). Moreover, the retro-Mannich reaction of $\mathbf{3 a}$ in the presence of $5 \mathrm{~mol} \%$ of $\mathrm{CuO}^{t} \mathrm{Bu}$ and $5 \mathrm{~mol} \%$ of $(R)$-DIPA$\mathrm{MeO}-\mathrm{BIPHEP}$ at $-60^{\circ} \mathrm{C}$ did not proceed at all, indicating that the very low yield of the proton-transfer Mannich reaction between 1a' and $\mathbf{2 a}$ was not attributed to the retro-Mannich reaction of $\mathbf{3 a}$ under basic conditions. The same diastereo- and enantioselectivities were observed both in the decarboxylative version and in the proton-transfer version, indicating that the same copper(I) intermediate was generated. It is reasonable that the proton-transfer version led to very low yield as $2 \mathrm{H}$ azirine $2 \mathbf{a}$ is a poor electrophile as described in literature ${ }^{25,28}$. As $2 \mathrm{H}$-azirine $\mathbf{2 a}$ is an imine base, it is also reasonable that the protonation of 2a by 1a might occur smoothly to give an iminium cation, which is a highly electrophilic species. Moreover, it was observed that the copper(I)-catalyzed decarboxylation protonation of $\mathbf{1 a}$ proceeded very slowly in the absence of $\mathbf{2 a}$ at $-60^{\circ} \mathrm{C}$, which indicated the interaction between $1 \mathrm{a}$ and 2a (the activation of $\mathbf{2 a}$ by $\mathbf{1 a}$ through a hydrogen-bonding effect can not be excluded completely at present). The difference of the electrophiles in the Mannich reaction resulted in different yields. The same tendency was also observed in the Mannich reaction of aliphatic $2 \mathrm{H}$-azirine $\mathbf{4 a}$ with $(R)$ DTBM-SEGPHOS as the ligand (Fig. 3c, d). It is obvious that the present acidic reaction conditions are superior to the classical basic proton-transfer reaction conditions in the construction of contiguous tetrasubstituted and quaternary stereocenters.

Transformations. Transformations of $\mathbf{3 a}$ were shown in Fig. 4. After protection of $\mathbf{3 a}$ with an acid chloride, the rearrangement of the aziridine moiety in $3 \mathbf{a}$ to an oxazoline group produced 6 in $63 \%$ yield with maintained enantioselectivity ${ }^{25}$.The reduction of cyano group by DIBAL-H afforded carbamate 7 in $60 \%$ yield after protection of the free amine with $\mathrm{Boc}_{2} \mathrm{O}$. Moreover, the acidic opening of the aziridine group in $\mathbf{3 a}$ with $\mathrm{HCl}$ proceeded smoothly to furnish amine $\mathbf{8}$ in $80 \%$ yield. Obviously, the primary alkyl chloride moiety in $\mathbf{8}$ allows further structure elaboration. At last, the absolute configurations of the stereocenters in $\mathbf{8}$ were determined by the X-ray analysis of its single crystals as depicted in Fig. 4, which led to the determination of the exact stereochemistry of 3a. Then, the absolute configurations in $\mathbf{3}$ and 5 were assigned tentatively by analogy (see Supplementary Fig. 40 and Supplementary Table 4 for details). 


\section{Table 2 Substrate scope of aromatic $2 H$-azirines ${ }^{a}$}

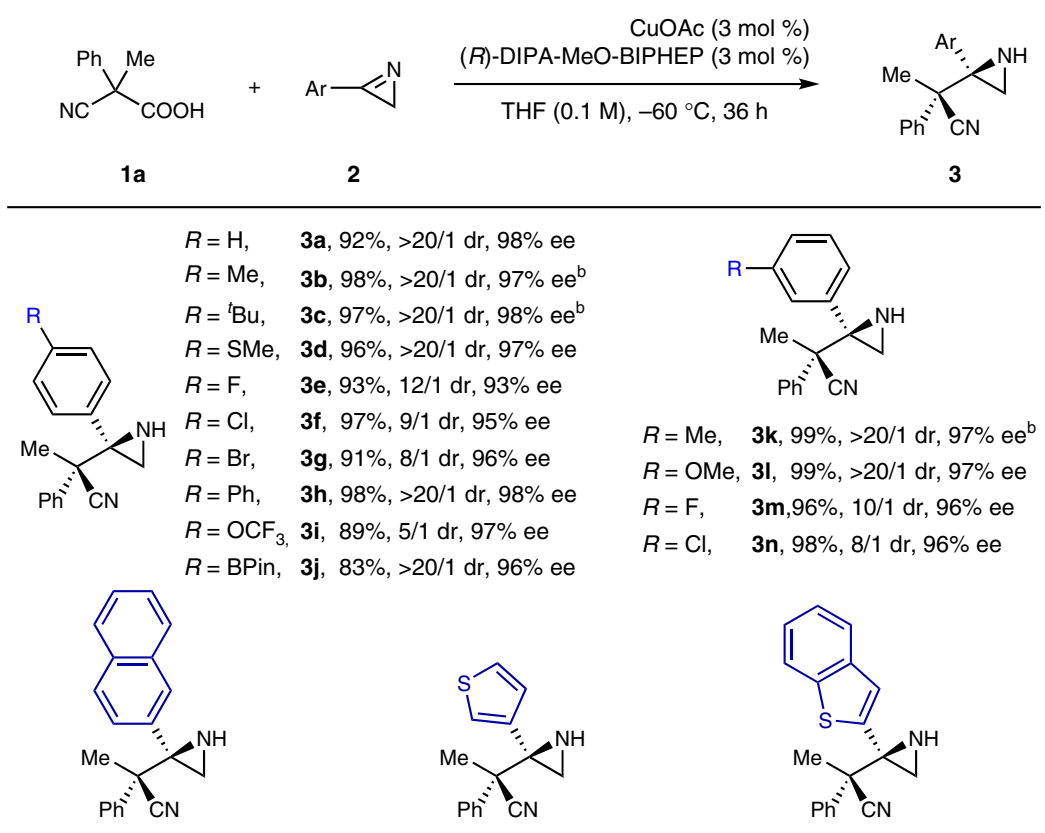

3o, $97 \%$, >20/1 dr, $97 \%$ ee

$3 p, 98 \%, 12 / 1 \mathrm{dr}, 96 \% \mathrm{ee}^{\mathrm{c}}$

$3 q, 99 \%,>20 / 1 d r, 93 \%$ ee $e^{d}$<smiles>C[C@](N)(c1ccccc1)[C@]1(c2ccc(COC(=O)COc3ccc(Cl)cc3Cl)cc2)CN1</smiles>

$3 r, 97 \%, 12 / 1 d r, 97 \%$ ee<smiles>C[C@](C#N)(c1ccccc1)[C@]1(c2ccc(COC(=O)Cc3ccc4c(c3)C(=O)c3ccccc3CO4)cc2)CN1</smiles>

3s, $99 \%, 11 / 1 \mathrm{dr}, 98 \% \mathrm{ee}^{\mathrm{e}}$<smiles>CCCNS(=O)(=O)c1ccc(C(=O)OCc2ccc([C@]3([C@](C)(N)c4ccccc4)CN3)cc2)cc1</smiles><smiles>CC(C)(C)OC(=O)NCC1(CC(=O)OCc2ccc([C@]3([C@](C)(C#N)c4ccccc4)CN3)cc2)CCCCC1</smiles>

3t, $98 \%, 11 / 1 d r, 98 \% e e^{e}$

$3 u, 99 \%, 12 / 1 d r, 98 \% e e^{e}$

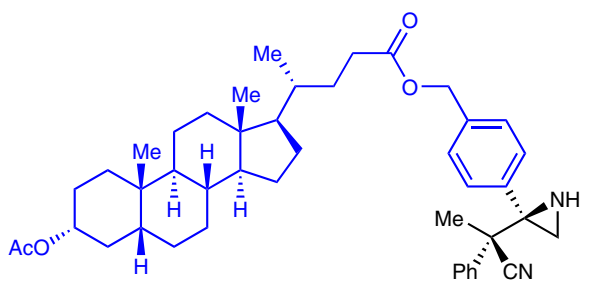

3v, $98 \%,>20 / 1 \mathrm{dr}, 98 \% \mathrm{de}^{\mathrm{e}, \mathrm{f}}$

a 1a: $0.3 \mathrm{mmol}, 2: 0.2 \mathrm{mmol}$. Isolated yield was reported. diastereoselectivity was determined by ${ }^{1} \mathrm{H}$ NMR analysis of reaction crude mixture. enantioselectivity was determined by chiral-stationary-phase HPLC analysis. ${ }^{b} 48 \mathrm{~h} .{ }^{c} 57 \mathrm{~h} .{ }^{\mathrm{d}} 90 \mathrm{~h} .{ }^{\mathrm{e}}$ 1a: $0.6 \mathrm{mmol}, \mathbf{2 :} 0.2 \mathrm{mmol} .6 \mathrm{~mol} \%$ of CuOAc and $6 \mathrm{~mol} \%$ of $(R)$-DIPA-MeO- BIPHEP were employed. $80 \mathrm{~h}$. ${ }^{\mathrm{f}}$ Diastereoselectivities ( $\mathrm{dr}$ and de) were determined by chiral-stationary-phase HPLC analysis 
Table 3 Substrate scope of aliphatic $\mathbf{2 H}$-azirines ${ }^{\mathbf{a}}$

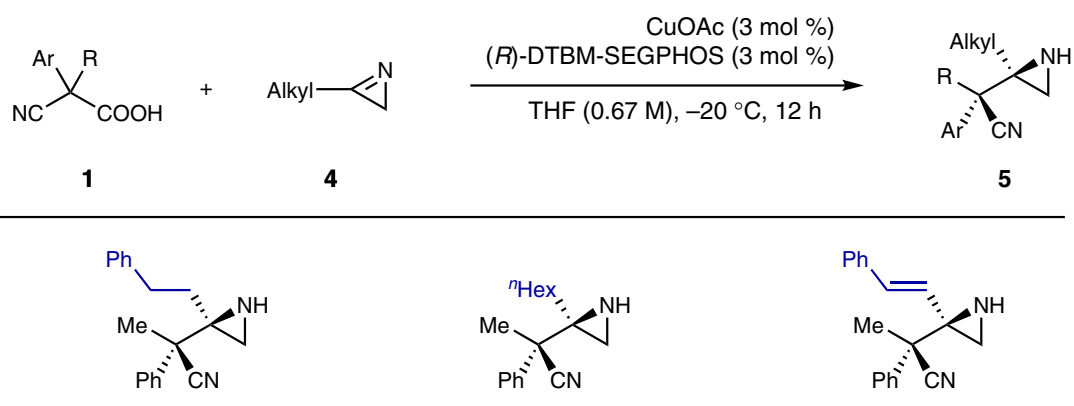

5a, $94 \%, 6 / 1 \mathrm{dr}, 91 \%$ ee<smiles>Cc1ccc([C@@](C)(C#N)[C@]2([14CH3])CN2)cc1</smiles>

5d, $91 \%, 10 / 1$ dr, $95 \%$ ee

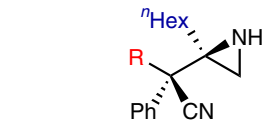

$\mathrm{R}=\mathrm{Et}, \quad \mathbf{5 g}, 62 \%, 2.4 / 1 \mathrm{dr}, 96 \%$ ee $\mathrm{R}=$ Allyl, 5h, 73\%, 2.9/1 dr, 96\% ee

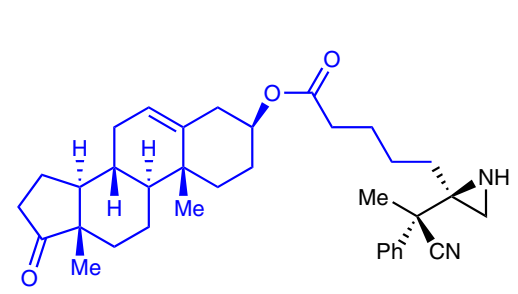

5j, $92 \%, 14.5 / 1 \mathrm{dr}, 96 \% \mathrm{de}^{\mathrm{b}}$ 5b, $96 \%, 10 / 1 \mathrm{dr}, 96 \%$ ee<smiles>C[C@@](C#N)(c1ccc(Cl)cc1)[C@@]1([14CH3])CN1</smiles>

$5 e, 62 \%, 11 / 1 d r, 96 \%$ ee 5c, $95 \%, 3.5 / 1 \mathrm{dr}, 93 \%$ ee<smiles>CC(C)(c1cccs1)[C@@]1(C#N)CN1</smiles>

5f, $92 \%, 10 / 1 \mathrm{dr}, 94 \%$ ee<smiles>COc1ccc2c(c1)c(CC(=O)OC1(C)CN1)c(N)n2C(=O)c1ccc(Cl)cc1</smiles>

5i, $81 \%, 10 / 1 \mathrm{dr}, 96 \%$ ee<smiles>CC1(C)OC[C@H]([C@H]2O[C@@H]3OC(C)(C)O[C@@H]3[C@H]2OC(C)(C)[C@]2([C@](C)(C#N)c3ccccc3)CN2)O1</smiles>

5k, $88 \%, 13 / 1 \mathrm{dr}, 96 \% \mathrm{de}^{\mathrm{b}}$

a 1: $0.5 \mathrm{mmol}$, 4: $0.2 \mathrm{mmol}$. 1 was added in $12 \mathrm{~h}$ with a syringe pump. Isolated yield was reported. diastereoselectivity was determined by ${ }^{1} \mathrm{H}$ NMR analysis of reaction crude mixture. Enantioselectivity was determined by chiral-stationary-phase HPLC analysis. ${ }^{b}$ Diastereoselectivities ( $\mathrm{dr}$ and de) were determined by chiral-stationary-phase HPLC analysis

\section{Discussion}

In conclusion, a copper(I)-catalyzed decarboxylative Mannich reaction between $\alpha, \alpha$-disubstituted cyanoacetic acids and various $2 \mathrm{H}$-azirines was disclosed, which efficiently constructed chiral aziridines bearing vicinal tetrasubstituted and acyclic quaternary stereogenic carbon centers. The present reaction enjoyed the advantages of mild reaction conditions, easy reaction protocol, broad substrate scope, and high to excellent stereoselectivity. The activation of basic $2 \mathrm{H}$-azirines by cyanoacetic acids, which might generate highly electrophilic iminium species, was proposed to be the key for the success of the present challenging reaction. At last, several transformations of the product were successfully carried out by means of the synthetically versatile cyano and aziridine groups. Expansion of both the present activation strategy and the mild nucleophile generation strategy through copper (I)-catalyzed decarboxylation in asymmetric catalysis is currently in progress in our laboratory.

\section{Methods}

General procedure for the synthesis of 3a. A dried $25 \mathrm{~mL}$ Schlenk tube equipped with a magnetic stirring bar was charged with $\mathrm{CuOAc}(2.94 \mathrm{mg}, 0.024 \mathrm{mmol})$ and $(R)$-DIPA-MeO-BIPHEP $(26.2 \mathrm{mg}, 0.024 \mathrm{mmol})$ in a glove box under Ar atmosphere. Anhydrous THF $(4 \mathrm{~mL})$ was added via a syringe. The mixture was stirred for $15 \mathrm{~min}$ to give a clear catalyst solution. Another dried $25 \mathrm{~mL}$ Schlenk tube equipped with a magnetic stirring bar was charged with aromatic $2 \mathrm{H}$-azirines 2a $(0.2 \mathrm{mmol}, 1.0$ equiv, $23.4 \mathrm{mg})$. The catalyst solution $(1.0 \mathrm{~mL})$ containing copper (I) complex $(0.006 \mathrm{mmol}, 0.03$ equiv) was added via a syringe. The reaction 
a<smiles>CC(C#N)(C(=O)O)c1ccccc1</smiles>

1a, 1.5 equiv
CuOAc (5 mol \%)

$(R)$-DIPA-MeO-BIPHEP (5 mol \%)

$\operatorname{THF}(0.1 \mathrm{M}),-60^{\circ} \mathrm{C}, 24 \mathrm{~h}$<smiles>C[C@](N)(c1ccccc1)[C@]1(c2ccccc2)CN1</smiles>

3a, $98 \%$ $>20 / 1 \mathrm{dr}, 98 \%$ ee b<smiles>N#CC(C#N)c1ccccc1</smiles>

1a', 1.5 equiv

C<smiles>[Y19]C(C#N)(C(=O)O)c1ccccc1</smiles>

1a, 3.0 equiv

d<smiles>N#CC(c1ccccc1)c1ccccc1</smiles>

1a', 3.0 equiv<smiles></smiles>

$2 a$ 2a

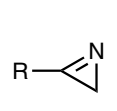

4a

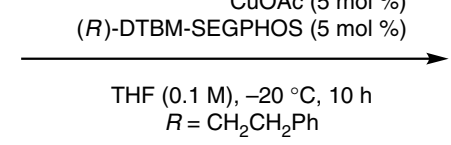

CuOAc $(5 \mathrm{~mol} \%)$ (R)-DTBM-SEGPHOS (5 mol \%) $\mathrm{LiO}^{t} \mathrm{Bu}(5 \mathrm{~mol} \%)$

THF (0.1 M), $-20^{\circ} \mathrm{C}, 10 \mathrm{~h}$ $R=\mathrm{CH}_{2} \mathrm{CH}_{2} \mathrm{Ph}$

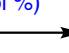<smiles>C[C@](C#N)(c1ccccc1)[C@@]1(c2ccccc2)CN1</smiles>

3a, $<5 \%$ $>20 / 1 \mathrm{dr}, 98 \%$ ee

5 a, $>99 \%$ $6 / 1 \mathrm{dr}, 91 \%$ ee<smiles>[2H][C@](C)(c1ccccc1)[C@@H]1CN1</smiles><smiles>[2H]C([2H])(c1ccccc1)[C@@]1(C#N)CN1</smiles>

Fig. 3 Demonstration of the strategy_ one substrate activation by the other. a Decarboxylative Mannich reaction of aromatic $2 \mathrm{H}$-azirine. $\mathbf{b}$ Protontransfer Mannich reaction of aromatic $2 \mathrm{H}$-azirine. c Decarboxylative Mannich reaction of aliphatic $2 \mathrm{H}$-azirine. $\mathbf{d}$ Proton-transfer Mannich reaction of aliphatic $2 \mathrm{H}$-azirine<smiles>CC(C)(c1ccccc1)[C@]1(c2ccccc2)CN=C(Br)O1</smiles>

$\mathrm{Ar}=3,5-\left(\mathrm{NO}_{2}\right)_{2}-\mathrm{C}_{6} \mathrm{H}_{3}$

$63 \%$ (two steps)

$>20 / 1 \mathrm{dr}, 98 \%$ ee

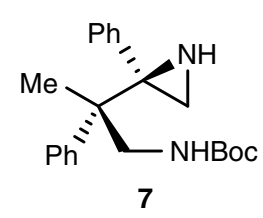

$60 \%$ (two steps) $>20 / 1 \mathrm{dr}, 98 \%$ ee

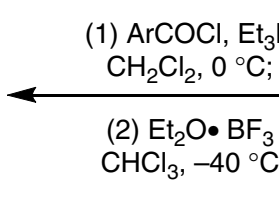

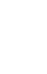

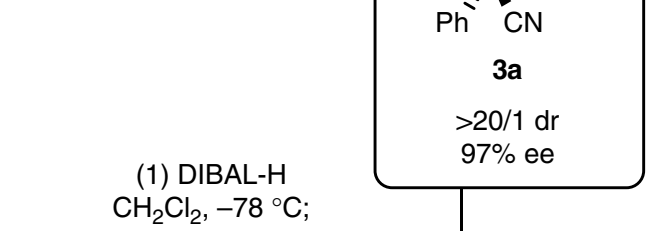

(2) $\mathrm{Boc}_{2} \mathrm{O}, \mathrm{Et}_{3} \mathrm{~N}$

$\mathrm{CH}_{2} \mathrm{Cl}_{2}, 0^{\circ} \mathrm{C}$ to rt

CuOAc $(5 \mathrm{~mol} \%)$

$(R)$-DIPA-MeO-BIPHEP (5 mol \%)
LiO $^{t} \mathrm{Bu}(5 \mathrm{~mol} \%)$

$\operatorname{THF}(0.1 \mathrm{M}),-60^{\circ} \mathrm{C}, 24 \mathrm{~h}$ 
Supplementary Information file. Any further relevant data are available from the authors on request.

Received: 20 February 2019 Accepted: 29 March 2019

Published online: 12 April 2019

\section{References}

1. Staunton, J. \& Weissman, K. J. Polyketide biosynthesis: a millennium review. Nat. Prod. Rep. 18, 380-416 (2001).

2. Magdziak, D. et al. Catalytic enantioselective thioester aldol reactions that are compatible with protic functional groups. J. Am. Chem. Soc. 127 7284-7285 (2005).

3. Fortner, K. C. \& Shair, M. D. Stereoelectronic effects dictate mechanistic dichotomy between $\mathrm{Cu}(\mathrm{II})$-catalyzed and enzyme-catalyzed reactions of malonic acid half thioesters. J. Am. Chem. Soc. 129, 1032-1033 (2007).

4. Yin, L., Kanai, M. \& Shibasaki, M. Nucleophile generation via decarboxylation: asymmetric construction of contiguous trisubstituted and quaternary stereocenters through a $\mathrm{Cu}(\mathrm{I})$-catalyzed decarboxylative Mannich-type reaction. J. Am. Chem. Soc. 131, 9610-9611 (2009).

5. Yin, L., Kanai, M. \& Shibasaki, M. Cu(I)-catalyzed decarboxylative aldol-type and Mannich-type reactions for asymmetric construction of contiguous trisubstituted and quaternary stereocenters. Tetrahedron 68, 3497-3506 (2012).

6. Hyodo, K., Kondo, M., Funahashi, Y. \& Nakamura, S. Catalytic enantioselective decarboxylative cyanoalkylation of imines by using palladium pincer complexes with C2-symmetric chiral bis(imidazoline)s. Chem. Eur. J. 19, 4128-4134 (2013).

7. Gajulapalli, V. P. R., Vinayagam, P. \& Kesavan, V. Organocatalytic asymmetric decarboxylative cyanomethylation of isatins using L-proline derived bifunctional thiourea. Org. Biomol. Chem. 12, 4186-4191 (2014).

8. Brunner, H. \& Schmidt, P. Naproxen derivatives by enantioselective decarboxylation. Eur. J. Org. Chem. 2000, 2119-2133 (2000).

9. Wang, Z.-L. Recent advances in catalytic asymmetric decarboxylative addition reactions. Adv. Synth. Catal. 355, 2745-2755 (2013).

10. Nakamura, S. Catalytic enantioselective decarboxylative reactions using organocatalysts. Org. Biomol. Chem. 12, 394-405 (2014).

11. Tanner, D. Chiral aziridines-their synthesis and use in stereoselective transformations. Angew. Chem. Int. Ed. Engl. 33, 599-619 (1994).

12. McCoull, W. \& Davis, F. A. Recent synthetic applications of chiral aziridines. Synthesis 2000, 1347-1365 (2000).

13. $\mathrm{Hu}, \mathrm{X}$. E. Nucleophilic ring opening of aziridines. Tetrahedron 60, 2701-2743 (2004).

14. Pineschi, M. Asymmetric ring-opening of epoxides and aziridines with carbon nucleophiles. Eur. J. Org. Chem. 2006, 4979-4988 (2006).

15. Schneider, C. Catalytic, enantioselective ring opening of aziridines. Angew. Chem. Int. Ed. 48, 2082-2084 (2009).

16. Krake, S. H. \& Bergmeier, S. C. Inter-and intramolecular reactions of epoxides and aziridines with $\pi$-nucleophiles. Tetrahedron 66, 7337-7360 (2010).

17. Yudin, A. K. Aziridines and Epoxides in Organic Synthesis (Wiley-VCH: Weinheim, 2006).

18. Ismail, F. M. D., Levitsky, D. O. \& Dembitsky, V. M. Aziridine alkaloids as potential therapeutic agents. Eur. J. Med. Chem. 44, 3373-3387 (2009).

19. Singh, G. S. Synthetic aziridines in medicinal chemistry: a mini-review. MiniRev. Med. Chem. 16, 892-904 (2016).

20. Khlebnikov, A. F. \& Novikov, M. S. Recent advances in $2 \mathrm{H}$-azirine chemistry. Tetrahedron 69, 3363-3401 (2013).

21. Huang, C.-Y. \& Doyle, A. G. The chemistry of transition metals with threemembered ring heterocycles. Chem. Rev. 114, 8153-8198 (2014).

22. Risberg, E. \& Somfai, P. Enantioselective addition of organolithium reagents to a $2 \mathrm{H}$-azirine. Tetrahedron Asymmetry 13, 1957-1959 (2002).

23. $\mathrm{Hu}, \mathrm{H}$. et al. Kinetic resolution of $2 \mathrm{H}$-azirines by asymmetric imine amidation. Angew. Chem. Int. Ed. 55, 10098-10101 (2016).

24. An, D. et al. Organocatalyzed nucleophilic addition of pyrazoles to $2 \mathrm{H}-$ azirines: asymmetric synthesis of 3,3-disubstituted aziridines and kinetic resolution of racemic $2 \mathrm{H}$-azirines. Chem. Commun. 52, 11211-11214 (2016).

25. Nakamura, S. \& Hayama, D. Enantioselective reaction of $2 \mathrm{H}$-azirines with phosphite using chiral bis(imidazoline)/zinc(II) catalysts. Angew. Chem. Int Ed. 56, 8785-8789 (2017).
26. Peng, Q., Guo, D., Bie, J. \& Wang, J. Catalytic enantioselective aza-benzoin reactions of aldehydes with $2 \mathrm{H}$-azirines. Angew. Chem. Int. Ed. 57, 3767-3771 (2018).

27. Nakamura, S., Hayama, D., Miura, M., Hatanaka, T. \& Funahashi, Y. Catalytic enantioselective reaction of $2 \mathrm{H}$-azirines with thiols using cinchona alkaloid sulfonamide catalysts. Org. Lett. 20, 856-859 (2018).

28. $\mathrm{Hu}, \mathrm{H}$. et al. Copper-catalyzed asymmetric addition of tertiary carbon nucleophiles to $2 \mathrm{H}$-azirines: access to chiral aziridines with vicinal tetrasubstituted stereocenters. Org. Lett. 20, 5601-5605 (2018).

29. Douglas, C. J. \& Overman, L. E. Catalytic asymmetric synthesis of all-carbon quaternary stereocenters. Proc. Natl. Acad. Sci. USA 101, 5363-5367 (2004)

30. Quasdorf, K. W. \& Overman, L. E. Catalytic enantioselective synthesis of quaternary carbon stereocentres. Nature 516, 181-191 (2014).

31. Feng, J., Holmes, M. \& Krische, M. J. Acyclic quaternary carbon stereocenter via enantioselective transition metal catalysis. Chem. Rev. 117, 12564-12580 (2017).

32. Gonthier, J. F., Wodrich, M. D., Steinmann, S. N. \& Corminboeuf, C. Branched alkanes have contrasting stabilities. Org. Lett. 12, 3070-3073 (2010).

33. Mitsunuma, H., Shibasaki, M., Kanai, M. \& Matsunaga, S. Catalytic asymmetric total synthesis of chimonanthine, folicanthine, and calycanthine through double Michael reaction of bisoxindole. Angew. Chem. Int. Ed. 51, 5217-5221 (2012)

34. Marek, I. et al. All-carbon quaternary stereogenic centers in acyclic systems through the creation of several C-C bonds per chemical step. J. Am. Chem. Soc. 136, 2682-2694 (2014).

35. Watson, C. G. et al. Construction of multiple, contiguous quaternary stereocenters in acyclic molecules by lithiation-borylation. J. Am. Chem. Soc 136, 17370-17373 (2014)

\section{Acknowledgements}

We gratefully acknowledge the financial support from the "Thousand Youth Talents Plan", the National Natural Science Foundation of China (No. 21672235 and No. 21871287), the Strategic Priority Research Program of the Chinese Academy of Sciences (No. XDB20000000), CAS Key Laboratory of Synthetic Chemistry of Natural Substances, and Shanghai Institute of Organic Chemistry.

\section{Author contributions}

L.Y. guided the research and wrote the manuscript. H.-J.Z. and Y.-C.X. performed the experiments.

\section{Additional information}

Supplementary Information accompanies this paper at https://doi.org/10.1038/s41467019-09750-5.

Competing interests: The authors declare no competing interests.

Reprints and permission information is available online at http://npg.nature.com/ reprintsandpermissions/

Journal peer review information: Nature Communications thanks the anonymous reviewers for their contribution to the peer review of this work.

Publisher's note: Springer Nature remains neutral with regard to jurisdictional claims in published maps and institutional affiliations.

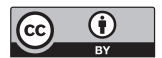

Open Access This article is licensed under a Creative Commons Attribution 4.0 International License, which permits use, sharing, adaptation, distribution and reproduction in any medium or format, as long as you give appropriate credit to the original author(s) and the source, provide a link to the Creative Commons license, and indicate if changes were made. The images or other third party material in this article are included in the article's Creative Commons license, unles indicated otherwise in a credit line to the material. If material is not included in the article's Creative Commons license and your intended use is not permitted by statutory regulation or exceeds the permitted use, you will need to obtain permission directly from the copyright holder. To view a copy of this license, visit http://creativecommons.org/ licenses/by/4.0/.

(c) The Author(s) 2019 